\title{
Simultaneous Determination of Bisphenol A and Bisphenol S Using Multi-Walled Carbon Nanotubes Modified Electrode
}

\author{
Xue Wang ${ }^{1, *}$, Mengjia $\mathrm{Li}^{1}$, Min Wu ${ }^{1}$, Yaru Shi ${ }^{1}$, Jiajia Yang ${ }^{2}$, Jiajia Shan ${ }^{1}$, Lifen Liu ${ }^{1}$ \\ ${ }^{1}$ School of Food and Environment, Dalian University of Technology, Panjin 124221, China \\ ${ }^{2}$ College of Materials Science and Engineering, Hebei University of Engineering, 199 South \\ Guangming Street, Handan 056038, China \\ *E-mail: wangxue@dlut.edu.cn.
}

doi: $10.20964 / 2018.12 .80$

Received: 18 August 2018 / Accepted: 12 October 2018 / Published: 5 November 2018

\begin{abstract}
A simple and sensitive electrochemical sensor based on multi-walled carbon nanotubes (MWCNTs) modified glassy carbon electrode was developed for the simultaneous determination of bisphenol A (BPA) and bisphenol S (BPS). The electrochemical behavior and electro-oxidation of BPA and BPS were investigated by cyclic voltammetry (CV) and differential pulse voltammetry (DPV). Experimental parameters such as $\mathrm{pH}$ of the buffer solution, accumulation time and scan rate have been optimized. The modified electrode exhibited outstanding electrocatalytic activity towards the oxidation of BPA and BPS and provided two separate oxidation current peaks enough to quantify BPA and BPS in mixture. The peak currents in DPV of BPA and BPS increased linearly with their concentrations in the ranges of $2 \times 10^{-6}$ to $3 \times 10^{-5} \mathrm{~mol} \mathrm{~L}^{-1}$ for BPA and $2 \times 10^{-5}$ to $8 \times 10^{-5} \mathrm{~mol} \mathrm{~L}^{-1}$ for BPS. The detection limits were $5 \times 10^{-7} \mathrm{~mol} \mathrm{~L}^{-1}$ for BPA and $4 \times 10^{-6} \mathrm{~mol} \mathrm{~L}^{-1}$ for BPS $(\mathrm{S} / \mathrm{N}=3)$, respectively. Furthermore, the developed sensor was successfully applied in determination of BPA and BPS in river water and thermal paper samples.
\end{abstract}

Keywords: Bisphenol A; Bisphenol S; Simultaneous determination; Multi-walled carbon nanotubes

\section{$\underline{\text { FULL TEXT }}$}

(C) 2018 The Authors. Published by ESG (www.electrochemsci.org). This article is an open access article distributed under the terms and conditions of the Creative Commons Attribution license (http://creativecommons.org/licenses/by/4.0/). 